\title{
GKN2 promotes oxidative stress-induced gastric cancer cell apoptosis via the Hsc70 pathway
}

Ziqiang Zhang ${ }^{1 \dagger}$, Hongyuan Xue ${ }^{1 \dagger}$, Yuanqiang Dong ${ }^{1 \dagger}$, Jun Zhang ${ }^{2}$, Yida Pan², Liubin Shi ${ }^{1}$, Panpan Xiong ${ }^{3}$, Jie Zhu ${ }^{2}$, Wenshuai $\mathrm{Li}^{2}$, Wanwei Zheng ${ }^{2}$, Jie Liu ${ }^{2 *}$ and Jianjun $\mathrm{Du}^{{ }^{*}}$

\begin{abstract}
Background: The GKN2 is a secretory protein, whose levels decrease in gastric cancer. The present study aimed to investigate the expression, function and mechanism of action of GKN2 in gastric cancer.

Methods: Molecular biology assays were performed to elucidate the function and underlying mechanisms of GKN2 in gastric cancer under stress-induced condition in vivo and in vitro. Clinical specimens were used to assess the correlation of GKN2 and prognosis.

Results: We found that overexpression of GKN2 significantly enhanced apoptosis and growth arrest in vitro. GKN2 expression increased in gastric cancer cells exposed to hydrogen peroxide and promoted reactive oxygen speciesinduced mitochondrial dysfunction and resulted in increased cell apoptosis via inhibition of NF-KB signaling pathway and activation of JNK signaling pathway through the direct interaction of GKN2 with Hsc70. Trefoil factor 1 might contribute to the tumor suppressing effects of GKN2. MiR-216a downregulated GKN2 expression. GKN2 also inhibited xenograft tumor growth and was an independent and significant prognostic factor for patients with gastric cancer treated with oxaliplatin.

Conclusions: Taken together, our data indicate that GKN2 may increase sensitivity of GC cells to the drugs which increase ROS levels in tumors. Inhibition of the interaction between GKN2 and Hsc70 could attenuate the effects induced by GKN2. GKN2 overexpression could be used to determine the subgroup of patients to obtain the more favorable outcome of oxaliplatin treatment and may be used as biomarker of the prognosis of this cancer.
\end{abstract}

Keywords: GKN2, Oxidative stress, Gastric cancer, Apoptosis

\section{Background}

Gastric cancer (GC) is one of the most common malignancies worldwide [1] and the second biggest health burden in China [2]. The pathogenic mechanisms of GC have been characterized as multifactorial and complex, but the specific set of factors that promote GC development and progression and their dynamic interactions remains poorly understood.

\footnotetext{
*Correspondence: jieliu@fudan.edu.cn; dujjp@hotmail.com

'Ziqiang Zhang, Hongyuan Xue and Yuanqiang Dong contributed equally to this work.

${ }^{2}$ Departments of Digestive Diseases, Huashan Hospital, Fudan University, 12 Middle Urumqi Road, Shanghai 200040, People's Republic of China

'Departments of General Surgery, Huashan Hospital, Fudan University, 12

Middle Urumqi Road, Shanghai 200040, People's Republic of China
}

Full list of author information is available at the end of the article
Oxidative stress, an imbalance between oxidant production and antioxidant activity, refers to the pathophysiology of a wide range of acute and chronic conditions [3]. Damage from oxidative stress is involved in many types of diseases, including neurological diseases, diabetes, atherosclerosis, arthritis, inflammation, and several types of cancer, including GC [4].

The tumor microenvironment is characterized by different stress conditions such as hypoxia and nutrient deprivation induced by defective tumor vasculature, or genotoxic and oxidative stress caused by rapid cell division or therapy [5-7]. Tumor cells need to manage these stresses, and tumor progression and ultimately patient outcome will be determined by the resistance of tumor cells to the different stresses they are exposed to.

(C) The Author(s). 2019 Open Access This article is distributed under the terms of the Creative Commons Attribution 4.0 International License (http://creativecommons.org/licenses/by/4.0/), which permits unrestricted use, distribution, and 
At the cellular level, the stress response depends on both the tumor energy status and its adaptive response, which contribute to the maintenance of cell survival. However, stress adaptation happens at the expenses of tumor proliferation; therefore, tumor cells need to develop strategies to survive stress and proliferate.

MicroRNAs (miRNA) participate in many normal biologic processes, including cell proliferation, differentiation, apoptosis, and organ development. Most miRNAs function by negatively regulating gene expression by directly binding to the $3^{\prime}$-untranslated region ( $3^{\prime}$-UTR) of a target gene mRNA, which induces mRNA cleavage or translational repression [8]. Mir-216a plays an important role in various kinds of cancers $[9,10]$. At the same time it also functions as a modulator in response to oxidative stress [11].

The gastrokine 2 (GKN2), also known as gastric dramatic down-related gene $(G D D R)$, was discovered and cloned for the first time by our team [12]. GKN2, a small $(\sim 18 \mathrm{kDa})$ protein belonging to the BRICHOS protein superfamily, is characterized by an approximately 100 amino acid BRICHOS domain, and plays a role in inflammatory diseases, dementia, and cancer $[13,14]$. While all BRICHOS proteins are secreted or processed to generate mature peptides, GKN2 is unique in being almost exclusively expressed within, and secreted by, the mucus-producing epithelial cells of the stomach $[12,13,15]$. GKN2 is evolutionary conserved in mammals and higher vertebrates $[13,16,17]$.

While GKN2 is abundantly expressed in surface mucus cells of the normal human stomach, its levels decrease in gastric adenocarcinoma as well as in tumor cell lines [12]. Conversely, GKN2 has been identified as the most upregulated gene in an expression microarray assay in the gastric transcriptome after eradication of Helicobacter pylori and cure of mucosal inflammation [18]. These observations suggest that GKNs, and, specifically, GKN2, play a vital role in the homeostatic regulation of mucosal immunity and/or in stomach-specific tumorsuppression. The mechanism of action of GKNs is still obscure, as well as their cognate receptors and the signaling pathways they regulate [13]. Interestingly, some studies on the GKN2/trefoil factor (TFF)1 heterodimer have suggested that GKN2 might have homeostatic and/ or tumor-suppressor activities via TFFs $[19,20]$.

To identify the impact of GKN2 loss in the context of stress, we analyzed the expression of GKN2 in GC cells exposed to hydrogen peroxide $\left(\mathrm{H}_{2} \mathrm{O}_{2}\right)$. Additionally, we investigated GKN2 effects on cell viability, proliferation and apoptosis under stress conditions. This study suggests that GKN2 might affect the sensitivity of GC cells to oxidative stress. Loss of GKN2 results in resistance of cells to oxidative stress, which can justify the tumor suppressor function of GKN2.

\section{Methods}

Cell culture

MGC-803 (MGC), SGC-7901 (SGC) and $293 \mathrm{~T}$ cells were obtained from the Cell Bank of Chinese Academy of Medical Science (Shanghai, China). GC cell lines were cultured in Roswell Park Memorial Institute-1640 containing 10\% fetal bovine serum (Invitrogen Life Technology, Carlsbad, CA, USA), penicillin $(100 \mathrm{U} / \mathrm{ml})$, and streptomycin $(100 \mathrm{mg} / \mathrm{ml}) .293 \mathrm{~T}$ cells were cultured in Dulbecco's modified Eagle's medium containing 10\% fetal bovine serum, penicillin $(100 \mathrm{U} / \mathrm{ml})$, and streptomycin $(100 \mathrm{mg} / \mathrm{ml}) . \mathrm{H}_{2} \mathrm{O}_{2}$ was purchased from Sangon Biotech (Shanghai, China).

\section{Cell transfection and overexpression}

Cells were transfected with small interfering RNA (siRNA) or plasmid vectors using Lipofectamine2000 (Invitrogen Life Technology) according to the manufacture's instruction. The sequences of siRNAs were as follows: siHsc70-1: 5'-GCUGGUCUCAAUGUACUUAT TUAAGUACAUUGAGACCAGCTT-3'; siHsc70-2: 5' GGCCAGUAUUGAGAUCGAUTTAUCGAUCUCAA UACUGGCCTT-3'; siTFF1-1: 5'-AGACAGAAUUGU GGUUUUCTT-3'; siTFF1-2: 5'-AUGGUAUUAGGA UAGAAGCACCAGG-3'. The siRNAs were from GenePharma (Shanghai, China). The pcDNA3 plasmid, pcDNA3-Hsc70 plasmid, pcDNA3-GKN2 plasmid, pcDNA3-GKN2 mutation plasmid and HA labeled ubiquitin enzyme (Ub-HA) plasmid were purchased from Fubio Biological technology (Suzhou, China). The mimics and inhibitors of miR-216a were purchased from Biotend (Shanghai, China).

\section{Cell proliferation and clonogenic assays}

Cells (1 000 cells/well) were seeded into 96-well plates for a cell counting kit-8 (CCK8) colorimetric assay (Dijindo, Japan) according to the manufacture's specifications. For the clonogenic assay, the cells were seeded into 6-cm plates and cultured for 14 days. The colonies on the plates were fixed with $4 \%$ paraformaldehyde, stained with crystal violet and counted.

\section{Western blotting}

Cell lysates were extracted with a cell lysis buffer (Beyotime, Hangzhou, China) and the protein concentration was quantified using an Enhanced BCA Protein Assay Kit (Beyotime). The primary antibodies used were as follows: anti-p65 (1:1000), anti- phosphorylated p65 (1:1000), anti-JNK (1:1000), anti-phosphorylated JNK (1: 1000), anti-glyceraldehyde 3-phosphate dehydrogenase (GAPDH) (1:1000), anti-cleaved caspase-3 (1:1000), anticleaved caspase-9 (1:1000), anti-cleaved PARP (1:1000) (CST, Danvers, MA, USA); anti-GKN2 (1:1000), antiHsc70 (1:1000) (Abcam, Cambridge, MA, USA). Anti- 
rabbit antibody (1:2000) and anti-mouse antibody antibodies (1:2000) (CST) were used as secondary antibodies. Western blot was performed as previously described [21].

Quantitative real-time polymerase chain reaction (qRT-PCR) QRT-PCR assays were conducted on a Bio-Rad quantitative PCR system (Hercules, CA, USA). For data analysis, raw counts of the target genes were normalized to those of the house keeping gene averaged for the same time point and condition. Counts are reported as fold change relative to the untreated control. All primers were designed and synthesized by Genewiz (Suzhou, China). The following primers were used: GKN2-F, $5^{\prime}$-AGAGCCTG CTTTATCCTGAAGA-3'; GKN2-R, 5'-ACTTGACCCA GGTGTATTTGC-3'. GAPDH-F, 5'-CTCACCGGATGC ACCAATGTT-3'; GAPDH-R, 5' -CGCGTTGCTCACAA TGTTCAT-3'. The miRcute Plus miRNA First-Strand cDNA Synthesis Kit was used for miRNA reversely transcription (TIANGEN BIOTECH CO., Beijing, China).

\section{Luciferase assays}

Using genomic DNA from $293 \mathrm{~T}$ cells as the template, the DNA sequence of the GKN2 3'-UTRs containing the potential miR-216a binding site was amplified and cloned into the XbaI site immediately downstream of the stop codon in the pGL3-promoter vector (Promega, Madison, WI, USA). Using four overlapping primers, the predicted miR-216a binding site was then replaced by a mutated $18 \mathrm{bp}-$ long fragment generating a pGL3 reporter plasmid with the mutated GKN2 3'-UTR. $293 \mathrm{~T}$ cells were seeded in 96-well plates and co-transfected with $5 \mathrm{ng}$ of pRL-renilla (Promega; internal control), 50 ng of the 3'-UTR pGL3-promoter reporter and $150 \mathrm{ng}$ of pSilencer-miR-126a (or pSilencer4.1CMV-negative). Forty-eight hours after transfection, the firefly and Renilla luciferase activities were assayed using the DualGlo Luciferase assay system (Promega). All experiments were performed in triplicate and repeated at least three times.

\section{Immunofluorescence and immunohistochemistry}

Cells were seeded in 6-well plates, incubated for $24 \mathrm{~h}$ and treated with $\mathrm{H}_{2} \mathrm{O}_{2}$ or phosphate-buffered saline (PBS) for $6 \mathrm{~h}$. The primary antibodies used were antiGKN2 and anti-Hsc70 (Abcam). 4',6-diamidino-2-phenylindole (DAPI; Solarbio, China) was used for nuclear staining. Alexa Fluor 488 anti-rabbit and Alexa Fluor ${ }^{\circ}$ 594 anti-mouse antibodies (CST) were used as secondary antibodies. Immunofluorescence assays were performed as previously described [22]. Tissue samples were fixed in $4 \%$ paraformaldehyde and embedded in paraffin. AntiGKN2 (1:200; Abcam) and anti-Ki67 (1:200; CST) were used as primary antibodies. Immunohistochemistry was performed as previously described [23]. GC tissues and adjacent non-malignant gastric tissues were obtained from the Huashan Hospital (Shanghai, China). The use of all tissue samples was approved by the Institutional Ethics Review Board of the Huashan Hospital.

\section{Superoxide dismutase activity}

After exposure to $\mathrm{H}_{2} \mathrm{O}_{2}$ treatment, superoxide dismutase activity of cells was detected by Total Superoxide Dismutase Assay Kit (Beyotime) according to the manufacturer's instruction.

\section{Flow cytometric analysis}

Flow cytometry was performed to analyze the cell cycle, apoptotic cells, mitochondrial membrane potential and reactive oxygen species (ROS) production. Dead Cell Apoptosis Kit (Invitrogen Life Technology) was used to determine cell apoptosis. The cells were analyzed for apoptosis immediately at the end of $\mathrm{H}_{2} \mathrm{O}_{2}$ treatment. MitoProbe $^{\mathrm{Tt}} \mathrm{JC}-1$ Assay Kit (Invitrogen Life Technology) was used to detect mitochondrial membrane potential. Tali $^{\text {Tix }}$ Cell Cycle Kit (Invitrogen Life Technology) was used to identify cell cycle. Cells were pretreated with $\mathrm{H}_{2} \mathrm{O}_{2}$ then cultured for another $24 \mathrm{~h}$ before cell cycle evaluation. ROS production was analyzed using the DCFH-DA probe (Beyotime). After exposure to various experimental conditions, flow cytometry was performed according to the manufacturer's instruction.

\section{Immunoprecipitation and sequential mass spectrometry} (MS)

Cells were lysed with a cell lysis buffer (CST) supplemented with complete protease inhibitor cocktail (Roche, Switzerland). Protein-G-Agarose beads (Invitrogen Life Technology) were incubated with anti-myc antibody or non-specific rabbit IgG antibody overnight. Protein lysates were added to the beads and incubated overnight. After SDS-PAGE, gel fixation, Coomassie staining (Merck, Kenilworth, NJ, USA), and mass spectrometry were carried out by PoolingMed Co., Ltd. (Hangzhou, China).

\section{Phospho-specific protein microarray analysis}

The Phospho Explorer Antibody Microarray was conducted by Full Moon BioSystems Inc. (Sunnyvale, CA, USA). Whole-cell lysates from cell cultures treated with $\mathrm{H}_{2} \mathrm{O}_{2}(300 \mu \mathrm{M})$ were harvested $6 \mathrm{~h}$ after treatment using a Protein Extraction Buffer (Full Moon BioSystems Inc.) and transferred to Full Moon BioSystems Inc., on dry ice. The array consists of 1318 phospho-specific antibodies. In brief, proteins were labeled with biotin and placed on pre-blocked microarray slides. After washing, the detection of total and phosphorylated proteins was conducted using Cy3-conjugated streptavidin. The expression of phosphorylated proteins was normalized to 
the corresponding total protein expression. Fold change was calculated as follows: phosphorylation of $\mathrm{H}_{2} \mathrm{O}_{2}$ treated cells/ phosphorylation of untreated cells. This experiment was carried out once. Where indicated, protein phosphorylation data were confirmed by western blotting.

\section{Tumor xenograft mouse models}

The animal care and experimental protocols were approved by the Animal Ethics Committee of Shanghai Medical College, Fudan University, China. Male BALB/c nude mice (4-weeks old) were obtained from Shanghai Research Center of the Southern model organisms. Mice were kept in specific pathogen-free conditions. The mice were randomly divided into groups before injection. Cells $\left(10^{7}\right)$ were suspended in $200 \mu \mathrm{l}$ PBS and subcutaneously injected in mice. Mice were treated with PL at the dose of $4 \mathrm{mg} / \mathrm{kg}$ body weight by intraperitoneal injection once every other day. Four weeks post-injection, the mice were sacrificed and the tumors were isolated and weighed.

\section{Databases and statistics}

We computationally screened microRNA targeting GKN2 using the miRWalk database (http://mirwalk. umm.uni-heidelberg.de/). Results are expressed as the mean \pm standard deviation (SD). The Student's t-test and one-way ANOVA were used to determine the significance of differences between groups. A $P$-value of $<0.05$ was considered significant and a P-value of $<$ 0.01 was considered very significant. Overall survival rates were calculated by the Kaplan-Meier method and differences were analyzed by the log-rank test. Univariate and multivariate analyses were performed using the Cox proportional hazards regression model. All statistical analyses were performed using the GraphPad Prism (GraphPad Software Inc., San Diego, CA, USA).

\section{Results}

Oxidative stress increase the expression of GKN2 in GC cell lines

To investigate whether stress could affect GKN2 expression, we examined the effects of $\mathrm{H}_{2} \mathrm{O}_{2}$ on GC cell lines (MGC and SGC). The observed enhancement of GKN2 expression in GC cell lines indicated that stress conditions induced GKN2 mRNA and protein expression (Fig. 1a, b). Immunofluorescence analysis also showed increased levels of GKN2 in GC cell lines with $\mathrm{H}_{2} \mathrm{O}_{2}$ treatment; in contrast, control cells, not treated with $\mathrm{H}_{2} \mathrm{O}_{2}$, had lower levels of GKN2 in the cytoplasm (Fig. 1c, d). Interestingly, we found $\mathrm{H}_{2} \mathrm{O}_{2}$ downregulated the expression of miR-216a (Fig. 1e), which was identified as a possible microRNA targeting GKN2 through a computational screen using an open access software. The mimics or inhibitors of miR-216a were transfected into GC cell lines and the expression of GKN2 was detected (Fig. 1f). Next, we investigated whether the expression of GKN2 was regulated by miR-216a in luciferase assays. We constructed luciferase reporter plasmids (in the pGL3 vector) with the luciferase coding region followed by the wild type or mutated 3'-untranslated region (UTR) of GKN2 and found that the luciferase activity of the plasmid with the wild type GKN2 3'-UTRs was significantly inhibited by miR-216a, while the luciferase activity of the reporter with the mutated GKN2 3'-UTR was not (Fig. 1g). These data suggested that miR-216a targets GKN2. We then tested the expression of GKN2 and miR216a in GC and their adjacent tissues and found that GKN2 was downregulated in GC tissues; inversely, miR216a was upregulated (Fig. 1h, i; Additional file 2: Table S1).

\section{GC cell lines overexpressing GKN2 are hypersensitive to oxidative stress}

To address the role of GKN2 on GC cells, we first overexpressed GKN2 in MGC and SGC cells using lentiviral vectors. Each GC cell line infected with GKN2 lentiviral vectors showed efficient overexpression of GKN2, as determined by qRT-PCR and western blot (Additional file 1: Figure S1a, b). We observed the effects of GKN2 on apoptosis of MGC and SGC cells and found that overexpression of GKN2 promoted apoptosis induced by oxidative stress (Fig. 2a, b). We also performed clonogenic assays and found that GKN2 overexpression notably suppressed clonogenic survival by inhibiting colony formation under oxidative stress, as shown in Fig. 2c-d. Cell cycle assays showed S-phase arrest in MGC and SGC cells after treatment with $\mathrm{H}_{2} \mathrm{O}_{2}$ and GKN2 overexpression (Fig. 2e). In addition, we found that GKN2 overexpression significantly decreased the viability of cells under oxidative stress (Fig. 2f). Taken together, our results demonstrated that GKN2 inhibited cell proliferation and promoted apoptosis in GC cells.

\section{Knockdown of GKN2 promotes the growth of GC cell lines subjected to oxidative stress}

To further assess the role of GKN2 in the proliferation and apoptosis of GC cells, the CRISPR/Cas9 system was used to knock out GKN2 in MGC and SGC cells. QRT-PCR and western blot assays were performed to confirm silencing of GKN2 at the mRNA and protein level (Additional file 1: Figure S1c, d). We found that silencing of GKN2 inhibited the apoptosis of cells after $\mathrm{H}_{2} \mathrm{O}_{2}$ treatment (Additional file 1: Figure S2a, b). Moreover, colony formation assays showed that silencing of GKN2 notably enhanced the 


\section{a}
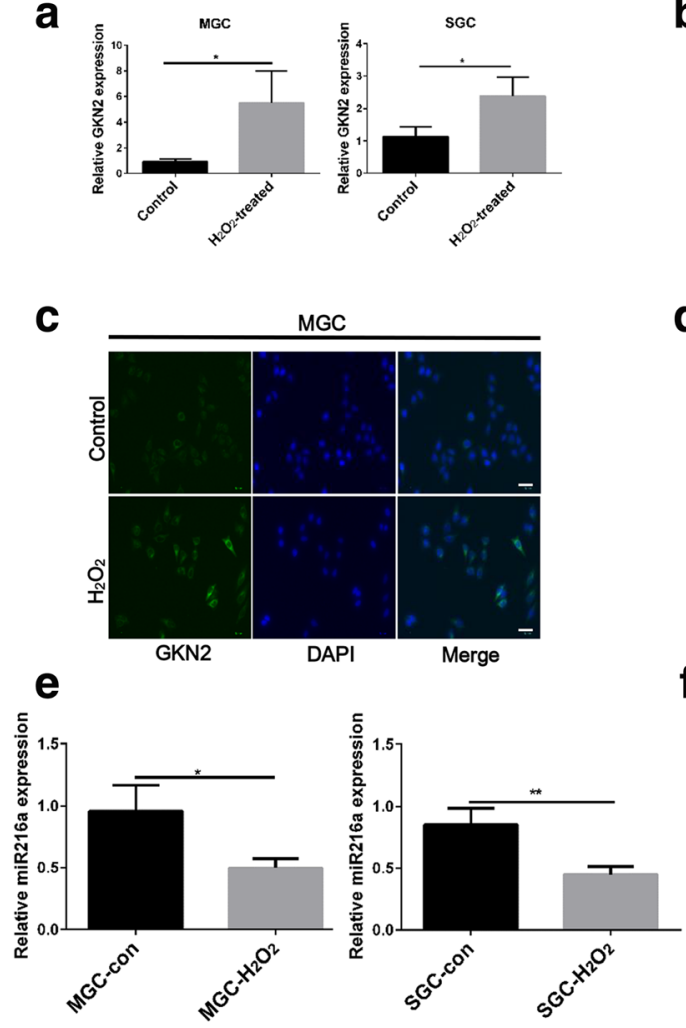

g

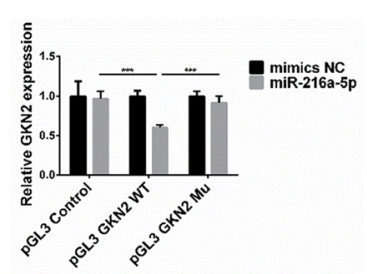

h

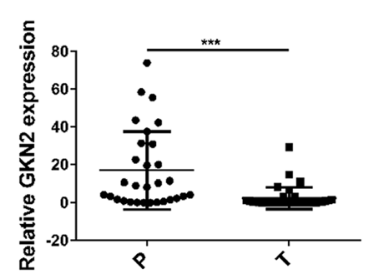

b

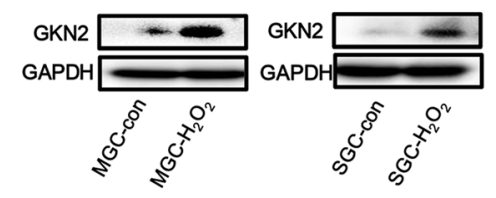

d
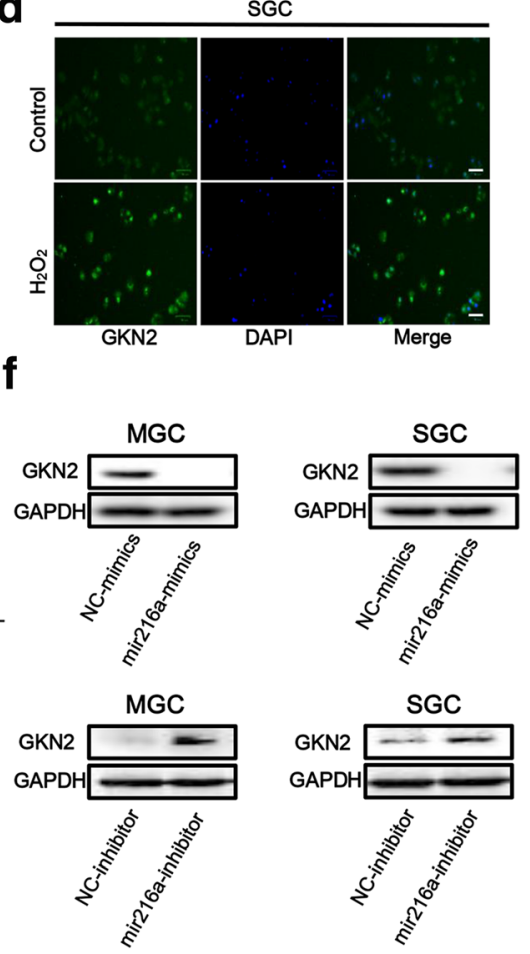

Fig. 1 Stress-induced GKN2 expression in GC cell lines. aQRT-PCR detection of GKN2 mRNA expression in MGC and SGC cells after $\mathrm{H}_{2} \mathrm{O}_{2}$ (300 uM) treatment for $6 \mathrm{~h}$. $\mathbf{b}$ GKN2 expression detected by western blotting after $\mathrm{H}_{2} \mathrm{O}_{2}(300 \mathrm{uM}$ ) treatment for $6 \mathrm{~h}$. $\mathbf{c}$ - $\mathbf{d}$ Immunofluorescence detection of GKN2 expression after $\mathrm{H}_{2} \mathrm{O}_{2}\left(300 \mathrm{uM}, 6\right.$ h) treatment. MGC and SGC cells were pre-treated with or without $\mathrm{H}_{2} \mathrm{O}_{2}(300 \mathrm{uM})$ for 6 h. Scale bar: 50 $\mu \mathrm{m}$. e QRT-PCR detected miR-216a expression after $\mathrm{H}_{2} \mathrm{O}_{2}(300 \mathrm{uM}, 6 \mathrm{~h})$ treatment. $\mathbf{f}$ Western blot detection of GKN2 expression in MGC and SGC cells transfected with miR-216a mimics (50 nM) and inhibitor (50 nM) for $48 \mathrm{~h}$. (g) MiR-216a significantly decreased luciferase report gene activities of GKN2 3'-UTR pGL3-promoter. $\mathbf{h}$-i GKN2 and miR-216a expression was detected by qRT-PCR in gastric tumor tissue and peripheral tissue. P: para-carcinoma tissues; T: tumor tissues. Dots are the values of GKN2 and mir-216a expression; the error bar indicates the SD. Asterisks indicate statistically significant differences from each other; ${ }^{*} p<0.05,{ }^{* *} p<0.01,{ }^{* * *} p<0.001$

clonogenic survival of the cells (Additional file 1: Figure S2c, d). In addition, knockout of GKN2 reduced the percentage of cells in S-phase arrest (Additional file 1: Figure S2e), and enhanced proliferation in both MGC and SGC cells with $\mathrm{H}_{2} \mathrm{O}_{2}$ treatment (Additional file 1: Figure $\mathrm{S} 2 \mathrm{f}$ ). These data further supported the 


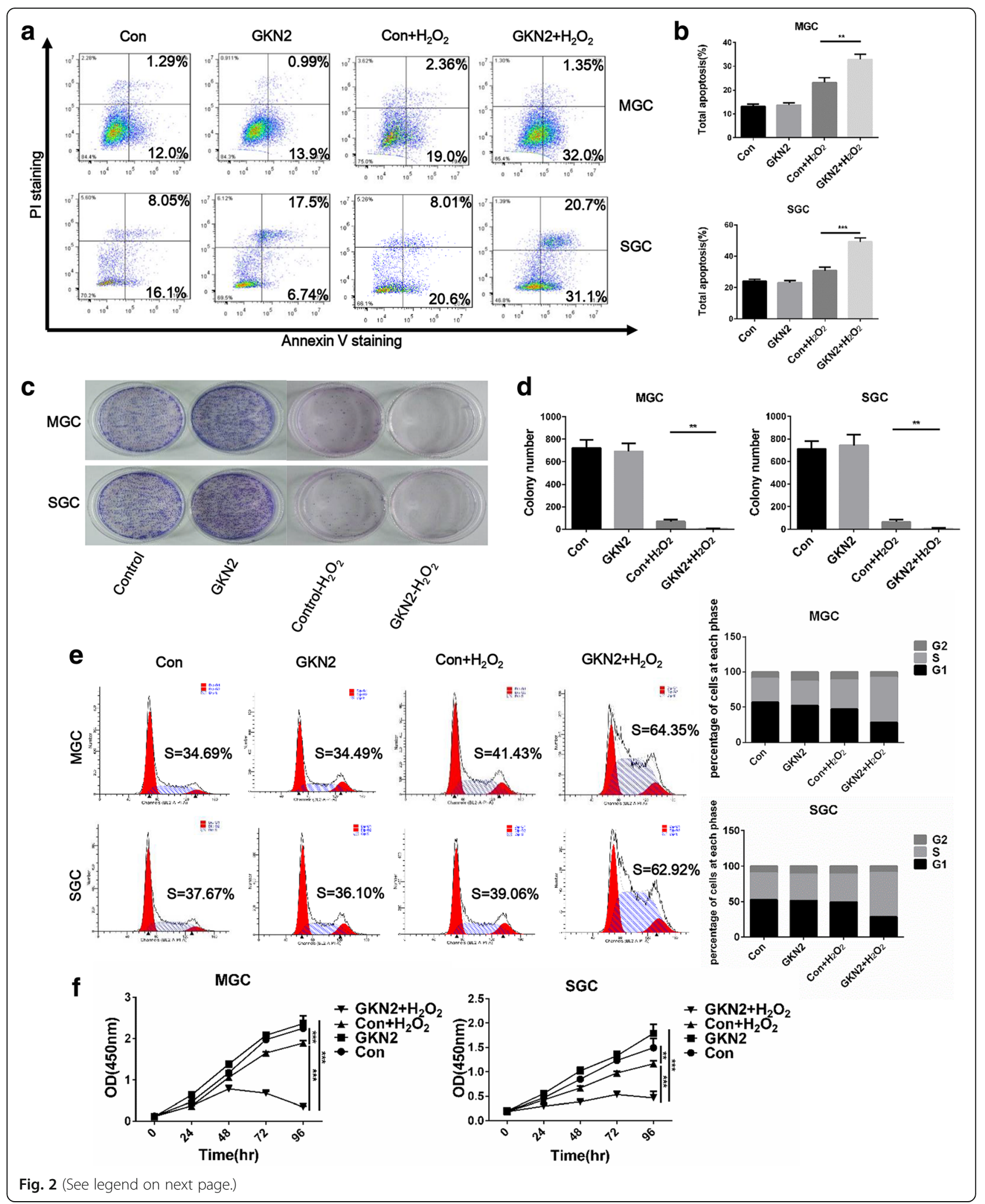


(See figure on previous page.)

Fig. 2 The stress-induced pro-apoptotic effect of GKN2 on GC cell lines. a-b Analyses of apoptosis with or without $\mathrm{H}_{2} \mathrm{O}_{2}$ (300 uM) concentration for $6 \mathrm{~h}$ in GC cell lines. c-d Comparison of colony formation in MGC and SGC cells with or without $\mathrm{H}_{2} \mathrm{O}_{2}$ (300 uM) pre-treatment for $6 \mathrm{~h}$. e Analyses of cell cycle after Pl staining in GC cell lines after $\mathrm{H}_{2} \mathrm{O}_{2}(300 \mathrm{uM})$ treatment for $6 \mathrm{~h}$. Data are presented as the mean of three independent experiments. $\mathbf{f}$ Comparison of proliferation in MGC and SGC cells with or without $\mathrm{H}_{2} \mathrm{O}_{2}$ (300 uM) pre-treatment for $6 \mathrm{~h}$. GKN2 overexpressing MGC cells (IC50 528.4 $\pm 29.5 \mu \mathrm{M}$ ) and SGC cells (IC50 539.2 $\pm 31.6 \mu \mathrm{M}$ ) were significantly more sensitive to $\mathrm{H}_{2} \mathrm{O}_{2}$ compared to control MGC cells (IC50 660.4 $\pm 29.4 \mu \mathrm{M}, P<0.01$ ) and SGC cells (IC50 663.0 $\pm 25.6 \mu \mathrm{M}, P<0.01$ ), respectively. Data are presented as mean \pm SD from three independent experiments with each running in triplicate. $\left(n=3,{ }^{* *} p<0.01,{ }^{* * *} p<0.001\right)$

inhibitory role of GKN2 in the regulation of cell proliferation and survival.

\section{GKN2 promotes ROS-induced mitochondrial dysfunction} We next examined whether the effect of $\mathrm{H}_{2} \mathrm{O}_{2}$ on GC cells was due to increased ROS levels, as it happens in other cancer types [24]. After treatment with $\mathrm{H}_{2} \mathrm{O}_{2}$, superoxide dismutase activity was significantly lower in GC cell lines overexpressing GKN2 (Additional file 1: Figure S3a). ROS levels in MGC and SGC cells were examined by flow cytometry using the redox-sensitive fluorescent probe 2'-,7'dichlorofluorescein diacetate (DCFH-DA). Exposure to $\mathrm{H}_{2} \mathrm{O}_{2}$ for $6 \mathrm{~h}$ led to an increase of ROS levels in the cells and pre-treatment with glutathione (GSH) reversed this effect, suggesting that GKN2 plays a role in stress-induced apoptosis in cancer cells (Additional file 1: Figure S3b). Mitochondria are important in the regulation of apoptosis. Loss of mitochondrial membrane potential $(\Delta \psi \mathrm{m})$ is harmful for cells and results in the release of cytochrome $\mathrm{C}$ into the cytosol [25] and apoptosis. Therefore, we analyzed whether $\mathrm{H}_{2} \mathrm{O}_{2}$ induced apoptosis was linked to mitochondrial homeostasis by flow cytometry upon staining with the mitochondrial membrane potential probe JC-1. We found that GKN2 contributed to loss of mitochondrial membrane potential after exposure to $\mathrm{H}_{2} \mathrm{O}_{2}$ for indicated time, while pre-treatment with GSH abolished this effect (Additional file 1: Figure S3c, d).

\section{GKN2 promotes apoptosis via the caspase pathway}

Next, to explore the mechanism through which GKN2 promotes stress-induced apoptosis, we analyzed by western blot the expression of cleaved-poly ADP ribose polymerase (PARP), cleaved-caspase- 9 , and cleaved-caspase-3 upon GKN2 overexpression or silencing. GKN2 overexpression was associated with increased expression of cleaved-PARP, cleaved-caspase- 3 and cleavedcaspase-9 after $\mathrm{H}_{2} \mathrm{O}_{2}$ treatment (Fig. 3a). Contrarily, silencing of GKN2 decreased the expression of these proteins (Fig. 3b). Pre-treatment with Z-VAD-FMK (VAD) reversed the stress-induced inhibition of MGC and SGC cell proliferation (Additional file 1: Figure S4a).

\section{Effects of GKN2 on NF-KB and JNK signaling pathways}

Next, we sought to investigate the modifications of the intracellular signaling network resulting from $\mathrm{H}_{2} \mathrm{O}_{2}$ treatment by performing a phosphoproteome analysis in GKN2 silenced cells and control cells: 1318 well-characterized phospho-specific antibodies were included in this array. GKN2 silenced SGC cells and control SGC cells were treated with $\mathrm{H}_{2} \mathrm{O}_{2}$. A pool of cell lysates including three independent GKN2 silenced SGC cells at a ratio of 1:1:1 was prepared and equally mixed with the cell lysate of control SGC cells. The oncogenic NF- $k B$ and JNK signaling pathways were selected from the complete data set. Only proteins with changes in their phosphorylation levels of $65 \%$ or less and $150 \%$ or more upon $\mathrm{H}_{2} \mathrm{O}_{2-}$ treatment (and after normalization to untreated control) were considered (Fig. 3c).

We examined the effects of GKN2 on these signaling pathways. We found that NF-kB phosphorylation was reduced in $\mathrm{H}_{2} \mathrm{O}_{2}$-treated MGC and SGC cells overexpressing GKN2 compared with control cells; also, the increased phosphorylation of JNK was observed in cells overexpressing GKN2 after $\mathrm{H}_{2} \mathrm{O}_{2}$ treatment (Fig. 3d). Pre-treatment with bay11-7082 (BAY) promoted stressinduced inhibition of proliferation in MGC and SGC cells (Fig. 3e). Conversely, the phosphorylation of NF-kB was increased and that of JNK was decreased in GKN2silenced cells (Fig. 3f). Pre-treatment with SP600125 (SP) reversed the stress-induced inhibition of proliferation of MGC and SGC cells (Fig. 3g). Therefore, the activation of JNK and the inactivation of NF- $\mathrm{kB}$ are important for GKN2-promoted stress-induced cell death.

\section{GKN2 sensitizes cell to death through its interaction with $\mathrm{Hsc70}$}

To further investigate the mechanism of GKN2, we looked for proteins that interact with GKN2. Cell lysates from GKN2-overexpressing and control cells were used for this purpose. We first immunoprecipitated GKN2 (myc-tagged) with an anti-myc monoclonal antibody. The immunocomplexes were then separated by sodium dodecyl sulfate-polyacrylamide gel electrophoresis, followed by band excision and in-gel digestion. Using LC-MS/MS-based quantitative proteomics, we identified more than 19 GKN2-interacting proteins, including 

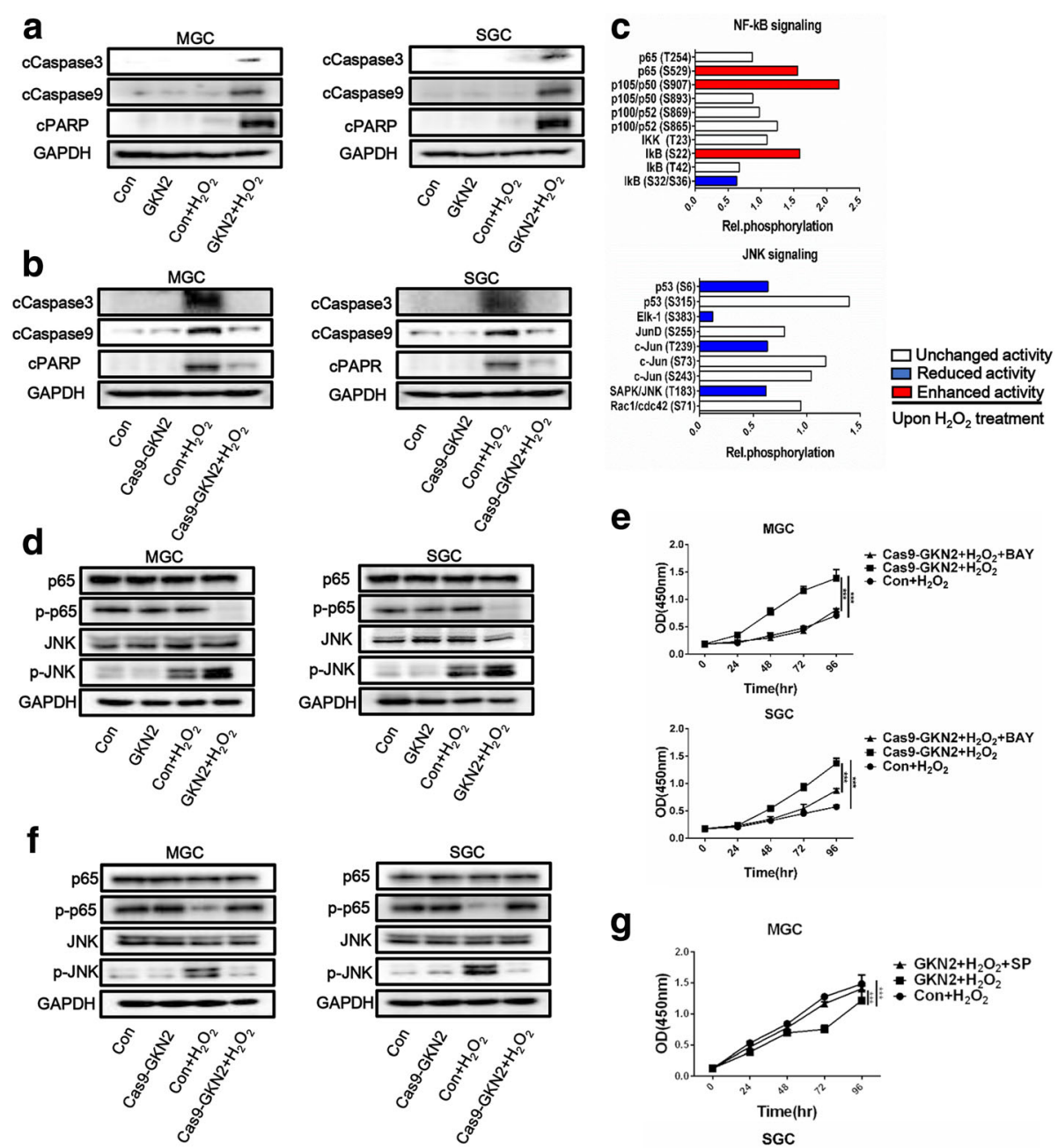

e
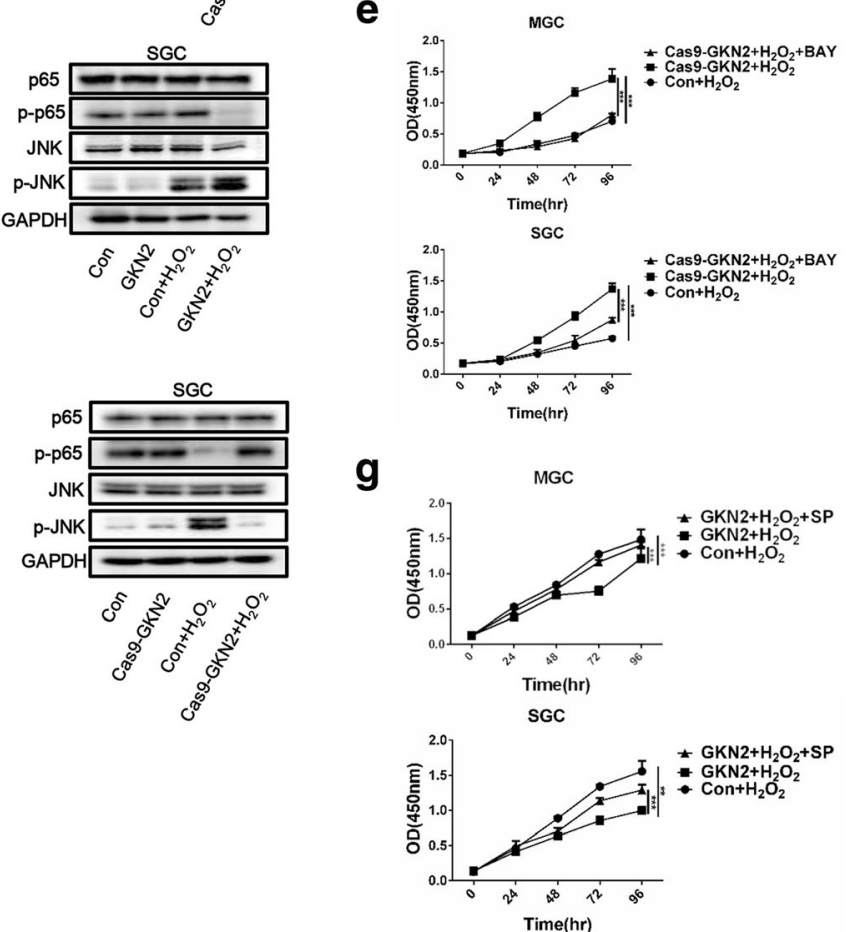

Fig. 3 Effects of GKN2 on NF-KB and JNK signaling. a-b Western blotting detection of pro-apoptotic protein in GC cell lines after $\mathrm{H}_{2} \mathrm{O}_{2}(300 \mathrm{uM})$ treatment for 6 h. c The Phospho Explorer Antibody Array was used to screen total cell lysates from untreated and $\mathrm{H}_{2} \mathrm{O}_{2}$-treated cell cultures. Data show fold change of indicated phosphoproteins upon $\mathrm{H}_{2} \mathrm{O}_{2}(300 \mathrm{uM})$ treatment for $6 \mathrm{~h}$ after normalization to total protein expression. $\mathbf{d} \& \mathbf{f}$ Western blotting detection of the protein expression and phosphorylation in GC cell lines after $\mathrm{H}_{2} \mathrm{O}_{2}(300 \mathrm{uM})$ treatment for $6 \mathrm{~h}$. (e) Comparison of the proliferation of $\mathrm{GC}$ cell lines after $\mathrm{H}_{2} \mathrm{O}_{2}(300 \mathrm{uM})$ treatment for $6 \mathrm{~h}$ with or without inhibition of NF-KB by $10 \mathrm{uM}$ bay $11-7082$. Cells were pretreated with the inhibitors for $2 \mathrm{~h}$ and maintained in culture. GKN2 silencing MGC cells (IC50 $676.7 \pm 27.9 \mu \mathrm{M})$ and SGC cells (IC50 $644.8 \pm 30.0 \mu \mathrm{M}$ ) with inhibition of NF-KB were significantly more sensitive to $\mathrm{H}_{2} \mathrm{O}_{2}$ compared to GKN2 silencing MGC cells (IC50 $807.4 \pm 45.4 \mu \mathrm{M}$, $P<0.05)$ and SGC cells (IC50 $836.8 \pm 30.5 \mu \mathrm{M}, \mathrm{P}<0.01)$, respectively. (g) Comparison of the proliferation of GC cell lines after $\mathrm{H}_{2} \mathrm{O}_{2}(300 \mathrm{uM})$ treatment for $6 \mathrm{~h}$ with or without inhibition of JNK by $10 \mathrm{uM} \mathrm{SP600125}$. Cells were pretreated with the inhibitors for $2 \mathrm{~h}$ and maintained in culture. GKN2 overexpressing MGC cells (IC50 603.4 $\pm 23.2 \mu \mathrm{M}$ ) and SGC cells (IC50 611.3 $\pm 25.5 \mu \mathrm{M}$ ) with inhibition of JNK were significantly less sensitive to $\mathrm{H}_{2} \mathrm{O}_{2}$ compared to GKN2 overexpressing MGC cells (IC50 528.4 $\left.\pm 29.5 \mu \mathrm{M}, P<0.05\right)$ and SGC cells (IC50 539.2 $\left.\pm 31.6 \mu \mathrm{M}, P<0.05\right)$, respectively. Data are presented as mean \pm SD from three independent experiments with each running in triplicate. $\left(n=3,{ }^{* *} p<0.01,{ }^{* * *} p<0.001\right)$

Hsc70 (Fig. 4a). Because Hsc70 regulates NF-kB activity, we decided to further investigate the putative interaction between GKN2 and Hsc70. In co-immunoprecipitation assays, we confirmed that GKN2 interacted with Hsc70 (Fig. 4b); specifically, the two proteins co-localized in cytoplasm (Fig. 4c). To further verify the binding specificity, we generated truncated mutants of GKN2 and Hsc70 tagged with myc and HA, and encompassing different domains in the two proteins. Co-immunoprecipitation data demonstrated that the deletion of the BRICHOS 
a

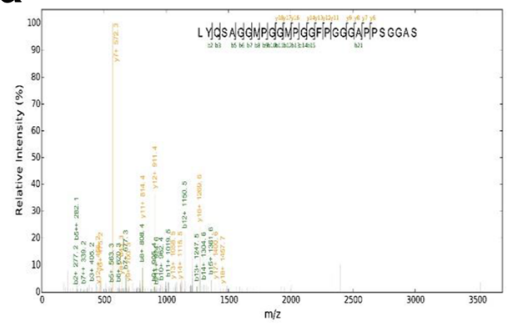

C

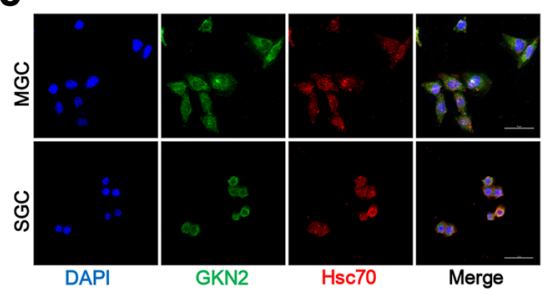

b

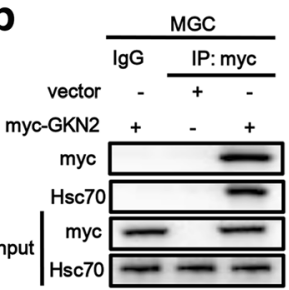

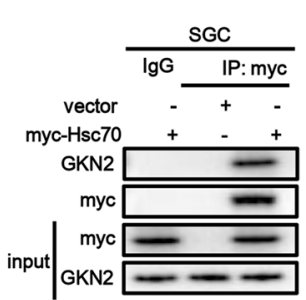

d
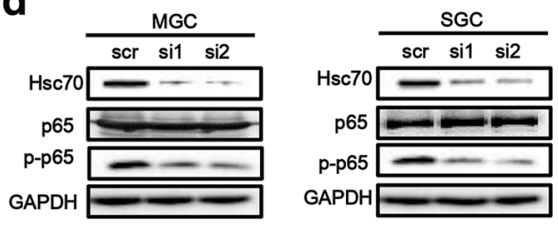

e
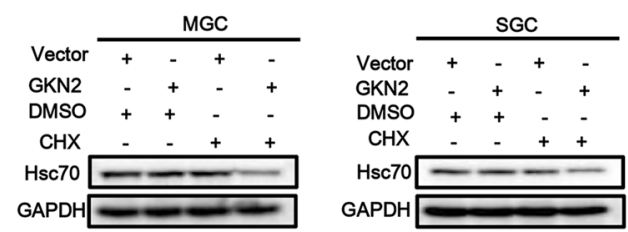

f
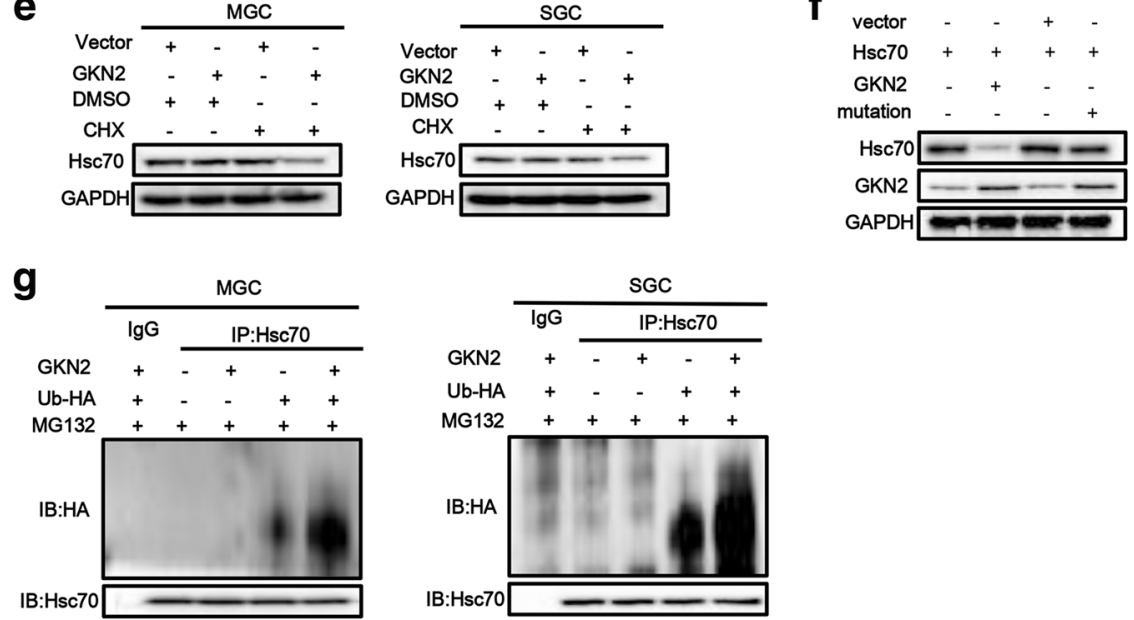

Fig. 4 GKN2 directly interacts with Hsc70. a Hsc70 was identified by MS as interactor of GKN2. b GKN2 interacted with Hsc70 in GC cell lines. MGC cells expressing myc-GKN2 and SGC cells expressing myc-Hsc70 were lysed, subjected to immunoprecipitation using anti-myc antibody, and detected using indicated antibodies. Input: cell lysate without immunoprecipitation. c Confocal laser-scanning detected the expression of GKN2 and Hsc70 in GC cell lines. Scale bar: $50 \mu \mathrm{m}$. d Effect of Hsc70 knockdown. Cells were transfected with siRNA to knockdown Hsc70 and cultured for $48 \mathrm{~h}$. Then indicated proteins were detected. e The stability assays of $\mathrm{Hsc70}$ after overexpression of GKN2. The cells were treated with $10 \mu \mathrm{M}$ cycloheximide (CHX) for $12 \mathrm{~h}$ then treated with $\mathrm{H}_{2} \mathrm{O}_{2}(300 \mathrm{uM}, 6 \mathrm{~h}$ ) before harvest. $\mathbf{f}$ The stability assays of Hsc70 after overexpression of GKN2 or its mutation. 293 T cells were transient co-transfected with Hsc70 and GKN2/GKN2 mutation/control plasmid and cultured for $24 \mathrm{~h}$. Then cells were treated with $10 \mu \mathrm{M}$ cycloheximide for the indicated times then treated with $\mathrm{H}_{2} \mathrm{O}_{2}$ ( $300 \mathrm{uM}, 6 \mathrm{~h}$ ) before harvest. $\mathbf{g}$ The expression and ubiquitination of Hsc70 after overexpression of GKN2. Cells were transient transfected with GKN2 and/or HA labeled ubiquitin enzyme (Ub-HA) and cultured for $24 \mathrm{~h}$. With exposure to MG132 (5uM, 2 h), cells were treated with $\mathrm{H}_{2} \mathrm{O}_{2}(300 \mathrm{uM}, 6 \mathrm{~h})$ before harvest. Then cells were lysed, subjected to immunoprecipitation using anti-Hsc70 antibody and detected using indicated antibodies. MG132: proteasome inhibitor

domain at the $\mathrm{N}$ terminus of GKN2 abrogated the interaction, suggesting that this domain is required for the interaction with Hsc70 (Additional file 1: Figure S5a). Moreover, the nucleotide-binding domain (NBD) of Hsc70 mediated the association with GKN2 (Additional file1: Fig. S5b). These data indicated that Hsc70 was a novel GKN2 interactor in vivo.

Knockdown of Hsc70 attenuated the effect of GKN2 on p65 phosphorylation in MGC and SGC cells (Fig. 4d) and GKN2 affected Hsc70 stability (Fig. 4e). Furthermore, through Co-IP assay we found Hsc70 interacted with p65 directly (Additional file 1: Figure S5c). Meanwhile, miR216a further promoted NF- $\mathrm{kB}$ pathway by downregulating GKN2 expression after $\mathrm{H}_{2} \mathrm{O}_{2}$ treatment (Additional file 1: Figure S5d). At same time, we found GKN2 induced the degradation of $\mathrm{Hsc70}$ (Fig. 4e) and promoted ubiquitinoylation of $\mathrm{Hsc70}$ in GC cells after $\mathrm{H}_{2} \mathrm{O}_{2}$ treatment through the detection of indicated proteins (Fig. 4g). However, the natural mutation of GKN2 could not facilitate the degradation of Hsc70 in $293 \mathrm{~T}$ cells were co-transfected with 
Hsc70 vector and GKN2 mutation vector then treated with $\mathrm{H}_{2} \mathrm{O}_{2}$ (Fig. 4f). The expression of GKN2 may suppress cancer cell proliferation through a TFF1dependent manner. To investigate if the oxidative stress-induced anti-proliferative and pro-apoptotic effects of GKN2 in gastric cancer cell were TFF1dependent, we overexpressed or knocked down TFF1 in GKN2-overexpressing and control cells. We found that synchronous overexpression of GKN2 and TFF1 promoted apoptosis of cells compared with other groups (Fig. 5a, b). Upon knockdown of TFF1 (Fig. 5c), CCK8 assays revealed that the overexpression of GKN2 in MGC and SGC cells still inhibited cell proliferation (Fig. 5d). Meanwhile, TFF1 augmented the effect of GKN2 on Hsc70 degradation (Fig. 5e) and promoted ubiquitinoylation (Fig. 5f). Taken together, these results demonstrated that the anti-proliferative and pro-apoptotic effects of GKN2 were TFF1-independent, although TFF1 could contribute to the effects of GKN2.

\section{GKN2 promotes the therapeutic effects of piperlongumine} (PL) in a xenograft mouse model

$\mathrm{PL}$, a natural product isolated from the long pepper Piper longum $L$, is selectively toxic to cancer cells in vitro and in vivo [24] and PL treatment increases ROS levels in cancer cells. To verify the function of GKN2 in vivo, MGC cells overexpressing GKN2 and SGC silenced for GKN2, or control MGC and SGC cells were subcutaneously injected in mice. Four weeks after injection of $\mathrm{PL}$, the mice were sacrificed and the tumors taken out and weighed. The mean tumor weight and volume were significantly lower in the GKN2-overexpressing group than in the control group (overexpressing the empty vector; Fig. 6a-c). On the other hand, silencing of GKN2 in SGC cells resulted in the development of larger tumors compared with the control cells and the effects of PL treatment was attenuated by administration of acetylcysteine (AC) (Fig. 6e-g). Consistently, the expression of GKN2 in the xenograft tumors was negatively correlated with Ki67, a cellular marker for proliferation (Fig. 6d, h). These data, together with the findings reported above, suggested that GKN2 repressed GC cells proliferation both in vitro and in vivo.

\section{Prognostic significance of GKN2 in patients with GC}

It has been reported that oxaliplatin increased generation of ROS, ultimately leading to the activation of apoptotic pathways [26]. To further evaluate the clinical significance of GKN2 in GC, we determined GKN2 levels in 121 patients with GC and treated with oxaliplatin after surgery (Fig. 6i). Importantly, the patients with higher GKN2 expression levels $(++$ and +++$)$ had better overall survival than those with lower GKN2 expression levels (- and +; Fig. 6j). Univariate analyses using the Cox hazard regression model identified GKN2 expression, stage and metastasis as prognostic indicators of overall survival for patients with GC (Table 1). Multivariate analysis further demonstrated the significant contribution of higher GKN2 expression to better outcomes of the patients (hazard ratio, 0.464; 95\% CI, 0.239-0.901; $P=0.023$; Table 1) and indicated that GKN2 was an independent and significant prognostic factor for patients with GC treated with oxaliplatin.

\section{Discussion}

In this study, we addressed the molecular mechanism underlying the tumor suppressor function of GKN2 in GC. GKN2 significantly reduced proliferation and promoted apoptosis of GC cells under stress. Overexpression of GKN2 and treatment with $\mathrm{H}_{2} \mathrm{O}_{2}$ synergistically inhibited cell proliferation and promoted apoptosis by upregulating cleaved (active) caspase- 3 and active caspase-9, important effectors of apoptosis. Interestingly, $\mathrm{H}_{2} \mathrm{O}_{2}$ induced the upregulation of GKN2 in GC cells. These findings are consistent with previous reports and strongly suggest that GKN2 functions as a tumor suppressor by regulating a set of proteins involved in apoptosis.

The expression of GKN2 decreases both in GC tissues and cell lines [27, 28], so we set out to determine whether this process was epigenetically regulated. However, we did not find any CpG island in the promoter region of GKN2. Interestingly, we found that miR-216a, which is upregulated in GC, could potentially inhibit GKN2 expression by binding to a plausible recognition site in the 3'-UTR of GKN2. Luciferase assays confirmed that miR-216a regulated the expression of GKN2. Additionally, miR-216a mimics suppressed the expression of GKN2 and GKN2 silencing in GC cells was reversed by miR-216a inhibitors. Furthermore, GKN2 expression was inversely correlated with that of miR216a in GC tissues and cell lines.

Overexpression of GKN2 and treatment with $\mathrm{H}_{2} \mathrm{O}_{2}$ synergistically promoted cell apoptosis by inhibiting NF$\mathrm{KB}$ and activating JNK. The inactivation of NF- $\mathrm{KB}$ by GKN2 has previously been reported in SGC cells. In this study, we have uncovered a new route for the inhibition of NF- $\mathrm{kB}$ pathway, mediated by GKN2 during oxidative stress. In cell based assays, we found that, after treatment with $\mathrm{H}_{2} \mathrm{O}_{2}$, GKN2 suppressed phosphorylation of NF- $\mathrm{KB}$ and the activation of this pathway. The effects of ROS, induced by $\mathrm{H}_{2} \mathrm{O}_{2}$, were largely indirect; however, our finding suggested the mechanism behind changes induced by GKN2 is stress-related.

GKN2, a stomach-specific gene, has been researched upon for more than 10 years; recently, it has been 

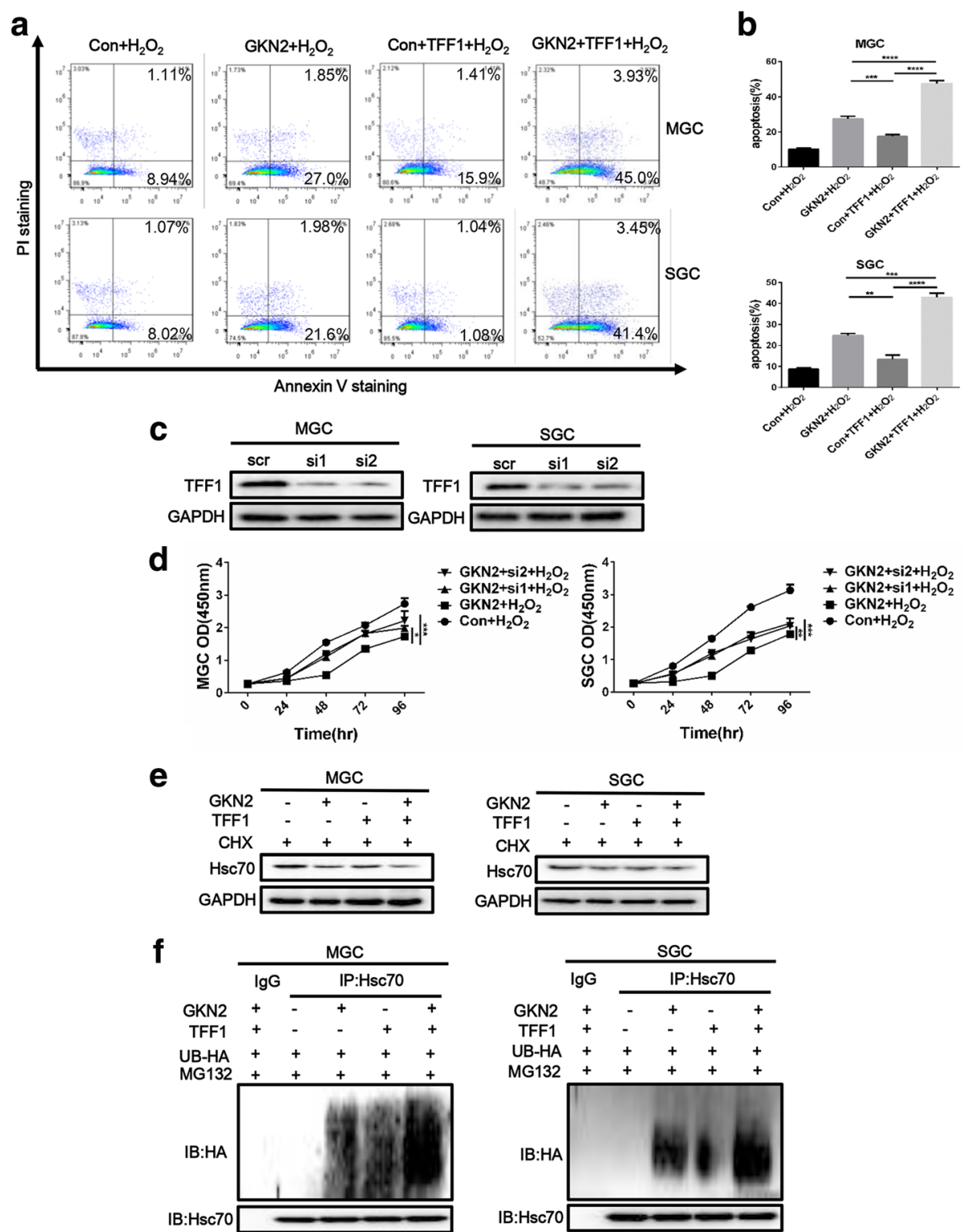

Fig. 5 TFF1 enhances the function of GKN2. a-b Analyses of apoptosis with or without TFF1 after $\mathrm{H}_{2} \mathrm{O}_{2}(300 \mathrm{uM}, 6 \mathrm{~h})$ treatment. c Detection of TFF1 expression after TFF1 was knockdown in GC cell lines. GC cells were transfected with siRNA (100 nM) and $24 \mathrm{~h}$ after transfection TFF1 expression was evaluated. $\mathbf{d}$ Comparison of the proliferation of GC cell lines with or without TFF1 knockdown. Cells were pre-treated with $\mathrm{H}_{2} \mathrm{O}_{2}$ (300 uM) for $6 \mathrm{~h}$. GKN2 overexpressing MGC cells (IC50 528.4 $\pm 29.5 \mu \mathrm{M}$ ) were significantly more sensitive to $\mathrm{H}_{2} \mathrm{O}_{2}$ compared to GKN2 overexpressing MGC cells with silence of TFF1 (IC50: si1 620.9 $\pm 33.6, P<0.05$; si2 618.4 $\pm 30.2, P<0.05$ ). In SGC cells, GKN2 overexpressing cells (IC50 539.2 $\pm 31.6 \mu \mathrm{M}$ ) were significantly more sensitive to $\mathrm{H}_{2} \mathrm{O}_{2}$ compared to GKN2 overexpressing cells with silence of TFF1 (IC50: si1 609.2 \pm 23.3, $P<0.05$; si2 $614.1 \pm 27.3, P<0.05$ ). e The stability assays of $\mathrm{Hsc70}$ after overexpression of TFF1 in control and GKN2-overexpressing GC cell lines. The cells were treated with $10 \mu \mathrm{M}$ cycloheximide for $12 \mathrm{~h}$ then treated with $\mathrm{H}_{2} \mathrm{O}_{2}(300 \mathrm{uM}, 6 \mathrm{~h}$ ). $\mathbf{f}$ The expression and ubiquitination of Hsc70 after overexpression of TFF1 in control and GKN2-overexpressing GC cell lines. Cells were treated with $\mathrm{H}_{2} \mathrm{O}_{2}(300 \mathrm{uM})$ for $6 \mathrm{~h}$. Data represent similar results from three independent experiments. $\left({ }^{* *} p<0.01,{ }^{* * *} p<0.001\right)$

proposed it acts as a tumor suppressor in many human cancer cell lines. The heterodimeric interaction between GKN2 and TFF1 played an important in inhibition of GC [29]; thereafter, its anti-proliferative and pro-apoptotic effects on GC cells were further substantiated and other mechanisms of GKN2 action emerged [30], including the recent indication that GKN2 functions as a GKN1 inhibitor, contributing to the homeostasis of gastric mucosa. GKN2 also play a significant role in regulation of gastric inflammation [31].

To identify the molecular details of GKN2 action on NF- $\mathrm{KB}$ and JNK, we investigated the protein(s), which 
a

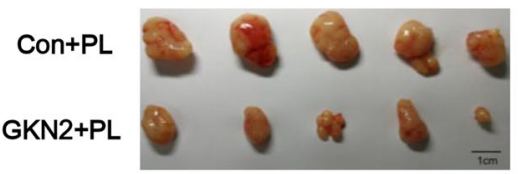

C

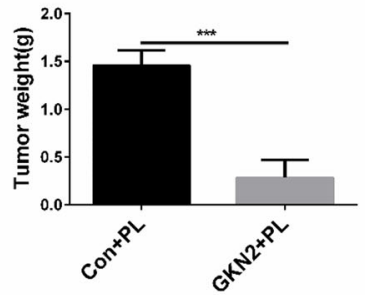

e

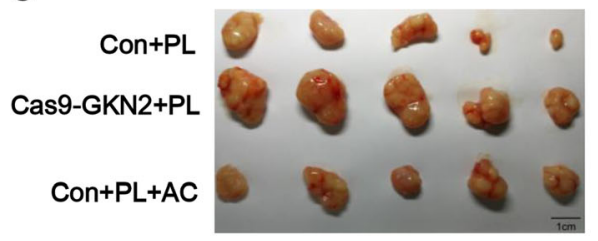

g

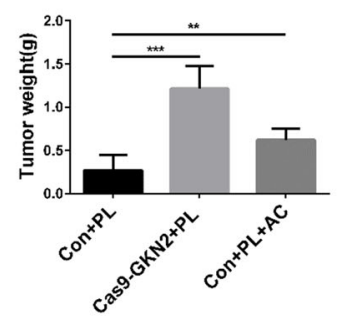

i

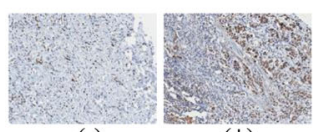

(-)

(+)

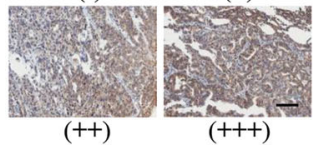

b
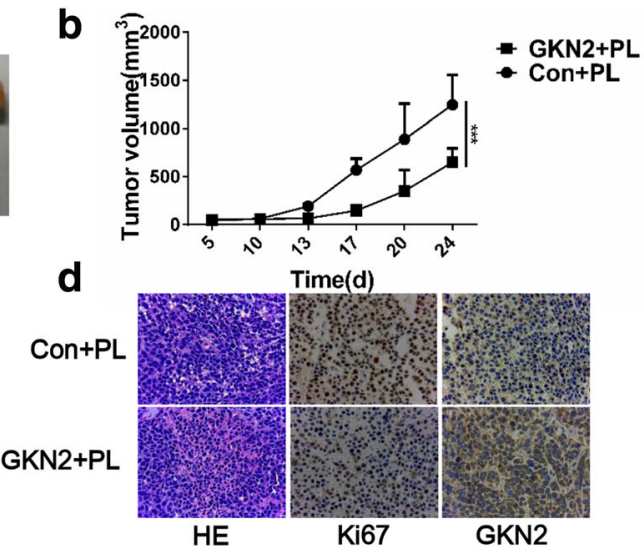

f
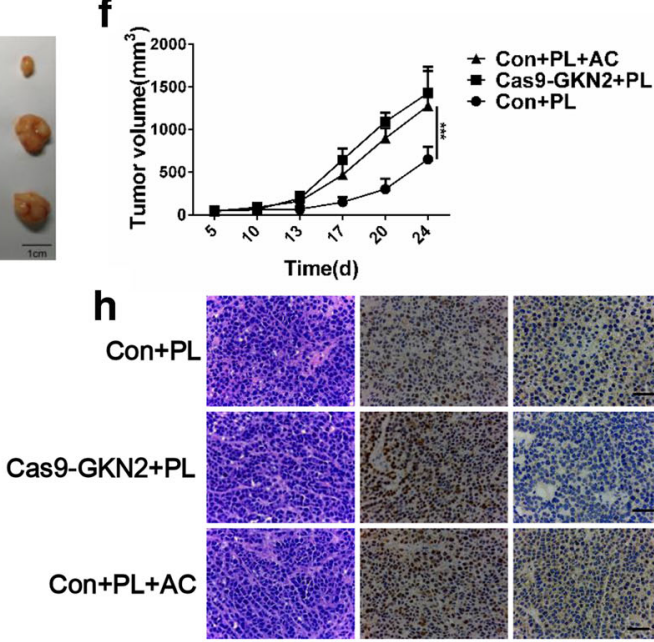

HE

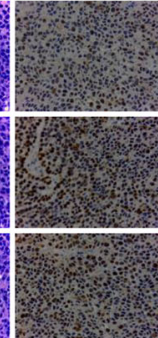

Ki67

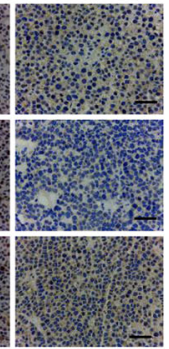

GKN2

j

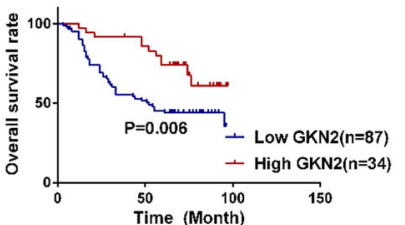

Fig. 6 GKN2 represses the tumorigenicity of GC cells under stress condition. a Forced expression of GKN2 suppresses the tumorigenicity of MGC in nude mice with PL treatment $(n=5)$. b-c Tumor volume and weights of xenografts tumors of MGC-con and MGC-GKN2 are significantly different. $\mathbf{d}$ Representative images of staining of HE, GKN2 and Ki67 in xenograft tumors of MGC-con and MGC-GKN2. Scale bar: $200 \mu$ m. e Silencing of GKN2 enhances the tumorigenicity of SGC in nude mice $(n=5)$. Mice were intraperitoneal injected with acetylcysteine $(\mathrm{AC}, 300 \mathrm{mg} / \mathrm{kg}) 2 \mathrm{~h}$ before administration of PL. (f-g) Tumor volume and weight of xenografts tumors of SGC-con and SGC-cas9-GKN2 were significantly different. Complementation of AC enhanced effect of the tumorigenicity in vivo. (h) Representative images of staining of HE, GKN2 and Ki67 in xenograft tumors. Scale bar: 200 m. (i) IHC staining of human GC tissues using GKN2-specific antibody; classification of samples according to the intensity of staining of GKN2 expression. Scale bar: $200 \mu \mathrm{m}$. j Kaplan-Meier curves for GC patients' overall survival in the patients with high GKN2 expression and low GKN2 expression $(n=121, p=0.006)$. The endpoint event was defined as mortality ${ }^{* *} p<0.01$, ${ }^{* *} p<0.001$

directly interact with GKN2, by co-immunoprecipitation followed by MS. We found that GKN2 bound Hsc70, which is important for NF- $\kappa B$ transcriptional activity, and promoted its degradation by ubiquitination. Several studies indicate that GKN2 forms a dimer with TFF1 through two heterologous disulfide bonds, and GKN2 and TFF1 show a strong correlation in clinical samples and related cell lines. A recent study has found that GKN2 could up-regulate levels of TFF1 in GKN2overexpressing GC. However, we found that the antiproliferative and pro-apoptotic effects of GKN2 were TFF1-independent. Therefore, although the findings 
Table 1 Analyses of time to disease progression in advance GC patients under the treatment of oxaliplatin

\begin{tabular}{|c|c|c|c|c|c|}
\hline \multirow[t]{2}{*}{ Factors } & \multirow[t]{2}{*}{$N$} & \multicolumn{2}{|l|}{ Univariate analysis } & \multicolumn{2}{|l|}{ Multivariate analysis } \\
\hline & & $\mathrm{HR}(95 \% \mathrm{Cl})$ & $P$ & $\mathrm{HR}(95 \% \mathrm{Cl})$ & $P$ \\
\hline \multicolumn{6}{|l|}{ Gender } \\
\hline Female & 34 & $1.140(0.643-2.022)$ & 0.653 & & \\
\hline Male & 87 & & & & \\
\hline \multicolumn{6}{|l|}{ Age } \\
\hline$<60$ & 51 & 1.345 (0.799-2.264) & 0.265 & & \\
\hline$\geq 60$ & 70 & & & & \\
\hline \multicolumn{6}{|l|}{ Stage } \\
\hline$|\&| \mid$ & 61 & $2.776(1.627-4.734)$ & $<0.001$ & $2.106(1.221-3.631)$ & 0.007 \\
\hline III \& IV & 60 & & & & \\
\hline \multicolumn{6}{|l|}{ Metastasis } \\
\hline No & 45 & $3.978(2.062-7.675)$ & $<0.001$ & $3.534(1.818-6.868)$ & $<0.001$ \\
\hline Yes & 76 & & & & \\
\hline \multicolumn{6}{|l|}{ Type } \\
\hline Diffuse & 105 & $0.658(0.283-1.571)$ & 0.331 & & \\
\hline Intestinal & 16 & & & & \\
\hline \multicolumn{6}{|l|}{ GKN2 } \\
\hline $\operatorname{Low}(-\&+)$ & 87 & $0.544(0.215-0.798)$ & 0.008 & $0.464(0.239-0.901)$ & 0.023 \\
\hline High $(++\&+++)$ & 34 & & & & \\
\hline
\end{tabular}

Staining intensity, negative: -, weak positive: + , moderate positive: ++ , strong positive: +++

presented in our study are in agreement with many of the experimental results presented in previous studies, our study comes to different conclusions regarding the mechanisms through which GKN2 mediates its effect.

ROS are toxic at certain levels, due to their reaction with proteins, lipids, and nucleic acids. The correct cellular response to ROS production is therefore critical in preventing further oxidative damage. ROS can induce both apoptotic and necrotic cell death depending on the severity of the oxidative stress damage [32-34] Genes targeted by canonical NF- $\mathrm{kB}$ promote cellular survival. Therefore, it is not surprising that ROS can modulate an NF- $\mathrm{kB}$ response and, on the other hand, ROS-induced damage is attenuated by NF- $\mathrm{kB}$ target genes.

The crosstalk between the NF- $k B$-induced cell survival pathway and the JNK-induced cell death pathway is affected by ROS production [35-37] and occurs in multiple ways [38-42]. This crosstalk is known to prevent sustained JNK activation and massive cell death through apoptosis and necrosis [36]. There is a positive feedback loop between ROS-dependent JNK activation and the generation of JNK/SAB-dependent mitochondrial ROS $[43,44]$. NF-кB signaling induces the transcription of both anti-apoptotic genes and genes involved in the downregulation of intracellular ROS levels. The production of antioxidants resulting from NF- $\mathrm{KB}$ activation plays a vital role in balancing ROS effects. Two major players in this context are manganese superoxide dismutase- 2 and catalase, both of which counteract apoptosis by neutralizing mitochondrial ROS $[45,46]$. On the other hand, ROS contribute to apoptosis by inducing mitochondrial outer-membrane permeabilization and JNK activation. The mitochondrial effect on apoptosis is largely mediated by proteins of the B-cell lymphoma 2 (Bcl2) family, such as Puma and Bim [47, 48]. As a result, caspase- 9 and caspase- 3 are activated and induce apoptosis. However, the pro-apoptotic activity of these molecules can be attenuated by the antiapoptotic proteins B-cell lymphoma-extra large (Bcl$\mathrm{XL}$ ) as well as $\mathrm{Bcl} 2$, whose expression is regulated by NF-кB [49].

\section{Conclusions}

In summary, we demonstrated GKN2 might increase sensitivity of GC cells to the drugs which increase ROS levels in tumors. Inhibition of the interaction between GKN2 and Hsc70 could attenuate the effects induced by GKN2. TFF1 could promote the function of GKN2, however, the anti-proliferative and pro-apoptotic effects of GKN2 were TFF1-independent. GKN2 overexpression could be used to determine the subgroup of patients to obtain the more favorable outcome of oxaliplatin treatment and might be used as biomarker of the prognosis of this cancer. 


\section{Additional files}

Additional file 1: Figure S1. Expression of GKN2 in GC cell lines. Figure S2. GKN2 silencing suppresses the sensitivity of GC cell lines to $\mathrm{H}_{2} \mathrm{O} 2$. Figure S3. $\mathrm{H} 2 \mathrm{O} 2$ induces ROS-dependent mitochondrial dysfunction. Figure S4. GKN2 inhibits proliferation via caspase pathway. Figure S5. GKN2 interacts with Hsc70 and regulates NF-kb pathway through Hsc70 (DOCX 2348 kb)

Additional file 2: Table S1. Clinicopathological characteristics of GC patients for analyzing the clinical significance of mir-216a expression $(n=35)$. (DOCX $14 \mathrm{~kb})$

\section{Abbreviations}

AC: acetylcysteine; BAY: Bay11-7082; CCK8: Cell counting kit-8; CHX: Cycloheximide; DCFH-DA: Redox-sensitive fluorescent probe 2'-,7'dichlorofluorescein diacetate; GC: Gastric cancer; GDDR: Gastric dramatic down-related gene; GKN2: Gastrokine 2; GSH: Glutathione; $\mathrm{H}_{2} \mathrm{O}_{2}$ : Hydrogen peroxide; Hsc70: Heat shock cognate 71 kDa protein; JNK: c-Jun N-terminal kinase; MGC: MGC-803; miRNA: MicroRNA; MS: Mass spectrometry; NBD: Nucleotide-binding domain; NF-KB: Nuclear factor kappa-light-chainenhancer of activated B cells; PBS: Phosphate-buffered saline; PL: Piperlongumine; qRT-PCR: Quantitative real-time polymerase chain reaction; ROS: Oxygen species; SD: mean \pm standard; SGC: SGC-7901; siRNA: Small interfering RNA; SP: SP600125; TFF: Trefoil factor; VAD: Z-VADFMK

\section{Acknowledgements}

We thank Professor Wei Li, Professor Guodong Yang, Professor Dahai Hu and Professor Shengqing Li for their generous help and precious advice.

\section{Authors' contributions}

Ziqiang Zhang, Hongyuan Xue, Jie Liu and Jianjun Du conceived the project. All authors wrote the manuscript.

\section{Funding}

This study was supported by the National Natural Science Foundation of China (grant No. 81270440).

\section{Availability of data and materials}

The datasets supporting the conclusions of this article are included within the article and its additional files.

\section{Ethics approval and consent to participate}

The study was approved by the ethics committee of the Huashan Hospital Fudan University and signed informed consent was obtained from each patient. All animal procedures were performed according to national guidelines and approved by the Institutional Committee of Fudan University for Animal Research.

\section{Consent for publication}

Informed consent was obtained from all individual participants included in the study.

\section{Competing interests}

The authors declare that they have no competing interests.

\section{Author details}

${ }^{1}$ Departments of General Surgery, Huashan Hospital, Fudan University, 12 Middle Urumqi Road, Shanghai 200040, People's Republic of China. ${ }^{2}$ Departments of Digestive Diseases, Huashan Hospital, Fudan University, 12 Middle Urumqi Road, Shanghai 200040, People's Republic of China. ${ }^{3}$ Departments of Digestive Diseases, Dongfang Hospital, Tongji University, Shanghai, China.
Received: 19 May 2019 Accepted: 22 July 2019

Published online: 05 August 2019

\section{References}

1. Torre LA, Bray F, Siegel RL, Ferlay J, Lortet-Tieulent J, Jemal A. Global cancer statistics, 2012. CA Cancer J Clin. 2015;65(2):87-108.

2. Chen W, Zheng $R$, Baade PD, Zhang S, Zeng H, Bray F, Jemal A, Yu XQ, He J. Cancer statistics in China, 2015. CA Cancer J Clin. 2016;66(2):115-32.

3. Bouvier E, Brouillard F, Molet J, Claverie D, Cabungcal JH, Cresto N, Doligez N, Rivat C, Do KQ, Bernard C, et al. Nrf2-dependent persistent oxidative stress results in stress-induced vulnerability to depression. Mol Psychiatry. 2017;22(12):1795.

4. Kruk J, Duchnik E. Oxidative stress and skin diseases: possible role of physical activity. Asian Pac J Cancer Prev. 2014;15(2):561-8.

5. Holcik M, Sonenberg N. Translational control in stress and apoptosis. Nat Rev Mol Cell Biol. 2005;6(4):318-27.

6. Liu B, Qian SB. Translational reprogramming in cellular stress response. Wiley Interdiscip Rev RNA. 2014;5(3):301-15.

7. Spriggs KA, Bushell M, Willis AE. Translational regulation of gene expression during conditions of cell stress. Mol Cell. 2010;40(2):228-37.

8. Bartel DP. MicroRNAs: genomics, biogenesis, mechanism, and function. Cell. 2004:116(2):281-97.

9. Wang RT, Xu M, Xu CX, Song ZG, Jin H. Decreased expression of miR216a contributes to non-small-cell lung cancer progression. Clin Cancer Res. 2014;20(17):4705-16

10. Xia H, Ooi LL, Hui KM. MicroRNA-216a/217-induced epithelial-mesenchymal transition targets PTEN and SMAD7 to promote drug resistance and recurrence of liver cancer. Hepatology. 2013;58(2):629-41.

11. Chinnappan M, Mohan A, Agarwal S, Dalvi P, Dhillon NK. Network of MicroRNAs mediate translational repression of bone morphogenetic protein Receptor-2: involvement in HIV-associated pulmonary vascular remodeling. J Am Heart Assoc. 2018;7(5).

12. Du JJ, Dou KF, Peng SY, Wang WZ, Wang ZH, Xiao HS, Guan WX, Liu YB, Gao ZQ. Down-regulated full-length novel gene GDDR and its effect on gastric cancer. Zhonghua Yi Xue Za Zhi. 2003;83(13):1166-8.

13. Menheniott TR, Kurklu B, Giraud AS. Gastrokines: stomach-specific proteins with putative homeostatic and tumor suppressor roles. Am J Physiol Gastrointest Liver Physiol. 2013;304(2):G109-21.

14. Hedlund J, Johansson J, Persson B. BRICHOS - a superfamily of multidomain proteins with diverse functions. BMC Res Notes. 2009;2:180

15. Martin TE, Powell CT, Wang Z, Bhattacharyya S, Walsh-Reitz MM, Agarwal K, Toback FG. A novel mitogenic protein that is highly expressed in cells of the gastric antrum mucosa. Am J Physiol Gastrointest Liver Physiol. 2003;285(2):G332-43

16. Menheniott TR, Peterson AJ, O'Connor L, Lee KS, Kalantzis A, Kondova I, Bontrop RE, Bell KM, Giraud AS. A novel gastrokine, Gkn3, marks gastric atrophy and shows evidence of adaptive gene loss in humans. Gastroenterology. 2010;138(5):1823-35.

17. Geahlen JH, Lapid C, Thorell K, Nikolskiy I, Huh WJ, Oates EL, Lennerz JK, Tian X, Weis VG, Khurana SS, et al. Evolution of the human gastrokine locus and confounding factors regarding the pseudogenicity of GKN3. Physiol Genomics. 2013:45(15):667-83.

18. Resnick MB, Sabo E, Meitner PA, Kim SS, Cho Y, Kim HK, Tavares R, Moss SF. Global analysis of the human gastric epithelial transcriptome altered by helicobacter pylori eradication in vivo. Gut. 2006;55(12):1717-24.

19. Westley BR, Griffin SM, May FE. Interaction between TFF1, a gastric tumor suppressor trefoil protein, and TFIZ1, a brichos domain-containing protein with homology to SP-C. Biochemistry. 2005:44(22):7967-75.

20. May FE, Griffin SM, Westley BR. The trefoil factor interacting protein TFIZ1 binds the trefoil protein TFF1 preferentially in normal gastric mucosal cells but the co-expression of these proteins is deregulated in gastric cancer. Int J Biochem Cell Biol. 2009:41(3):632-40.

21. Zhu J, Zhang Z, Zhang Y, Li W, Zheng W, Yu J, Wang B, Chen L, Zhuo Q, Chen $L$, et al. MicroRNA-212 activates hepatic stellate cells and promotes liver fibrosis via targeting SMAD7. Biochem Biophys Res Commun. 2018;496(1):176-83.

22. Thanomkitti K, Fong-Ngern K, Sueksakit K, Thuangtong R, Thongboonkerd V. Molecular functional analyses revealed essential roles of HSP90 and Lamin a/C in growth, migration, and self-aggregation of dermal papilla cells. Cell Death Discov. 2018;4:53 
23. Kikuchi Y, Kunita A, Iwata C, Komura D, Nishiyama T, Shimazu K, Takeshita K, Shibahara J, Kii I, Morishita Y, et al. The niche component periostin is produced by cancer-associated fibroblasts, supporting growth of gastric cancer through ERK activation. Am J Pathol. 2014;184(3):859-70.

24. Raj L, Ide T, Gurkar AU, Foley M, Schenone M, Li X, Tolliday NJ, Golub TR, Carr SA, Shamji AF, et al. Corrigendum: selective killing of cancer cells by a small molecule targeting the stress response to ROS. Nature. 2015;526(7574):596.

25. Weinberg SE, Chandel NS. Targeting mitochondria metabolism for cancer therapy. Nat Chem Biol. 2015;11(1):9-15.

26. Um HJ, Kwon TK. Protective effect of melatonin on oxaliplatin-induced apoptosis through sustained Mcl-1 expression and anti-oxidant action in renal carcinoma Caki cells. J Pineal Res. 2010;49(3):283-90.

27. Dai J, Qian C, Su M, Chen M, Chen J. Gastrokine-2 suppresses epithelial mesenchymal transition through PI3K/AKT/GSK3beta signaling in gastric cancer. Tumour Biol. 2016;37(9):12403-10.

28. Dokhaee F, Mazhari S, Galehdari M, Bahadori Monfared A, Baghaei K. Evaluation of GKN1 and GKN2 gene expression as a biomarker of gastric cancer. Gastroenterol Hepatol Bed Bench. 2018;11(Suppl 1):S140-5.

29. Kim O, Yoon JH, Choi WS, Ashktorab H, Smoot DT, Nam SW, Lee JY, Park WS: Heterodimeric interaction between GKN2 and TFF1 entails synergistic antiproliferative and pro-apoptotic effects on gastric cancer cells. Gastric Cancer2017.

30. Ouyang J, Pan X, Lin H, Hu Z, Xiao P, Hu H. GKN2 increases apoptosis, reduces the proliferation and invasion ability of gastric cancer cells through down-regulating the JAK/STAT signaling pathway. Am J Transl Res. 2017:9(2):803-11.

31. Menheniott TR, O'Connor L, Chionh YT. Loss of gastrokine-2 drives premalignant gastric inflammation and tumor progression. J Clin Invest. 2016;126(4):1383-400.

32. Saito Y, Nishio K, Ogawa Y, Kimata J, Kinumi T, Yoshida Y, Noguchi N, Niki E. Turning point in apoptosis/necrosis induced by hydrogen peroxide. Free Radic Res. 2006;40(6):619-30.

33. Takeda M, Shirato I, Kobayashi M, Endou H. Hydrogen peroxide induces necrosis, apoptosis, oncosis and apoptotic oncosis of mouse terminal proximal straight tubule cells. Nephron. 1999;81(2):234-8.

34. Teramoto S, Tomita T, Matsui H, Ohga E, Matsuse T, Ouchi Y. Hydrogen peroxide-induced apoptosis and necrosis in human lung fibroblasts: protective roles of glutathione. Jpn J Pharmacol. 1999;79(1):33-40.

35. Reuther-Madrid JY, Kashatus D, Chen S, Li X, Westwick J, Davis RJ, Earp HS, Wang CY, Baldwin Jr AS, Jr.: The p65/RelA subunit of NF-kappaB suppresses the sustained, antiapoptotic activity of Jun kinase induced by tumor necrosis factor. Mol Cell Biol 2002, 22(23):8175-8183.

36. Tang F, Tang G, Xiang J, Dai Q, Rosner MR, Lin A. The absence of NFkappaB-mediated inhibition of c-Jun $\mathrm{N}$-terminal kinase activation contributes to tumor necrosis factor alpha-induced apoptosis. Mol Cell Biol. 2002;22(24):8571-9.

37. Morgan MJ, Kim YS, Liu ZG. TNFalpha and reactive oxygen species in necrotic cell death. Cell Res. 2008;18(3):343-9.

38. Morgan MJ, Liu ZG. Reactive oxygen species in TNFalpha-induced signaling and cell death. Mol Cells. 2010;30(1):1-12.

39. Wullaert A, Heyninck K, Beyaert R. Mechanisms of crosstalk between TNFinduced NF-kappaB and JNK activation in hepatocytes. Biochem Pharmacol. 2006;72(9):1090-101.

40. Nakano H, Nakajima A, Sakon-Komazawa S, Piao JH, Xue X, Okumura K. Reactive oxygen species mediate crosstalk between NF-kappaB and JNK. Cell Death Differ. 2006;13(5):730-7.

41. Papa S, Bubici C, Zazzeroni F, Pham CG, Kuntzen C, Knabb JR, Dean K, Franzoso G. The NF-kappaB-mediated control of the JNK cascade in the antagonism of programmed cell death in health and disease. Cell Death Differ. 2006;13(5):712-29.

42. Morgan MJ, Kim YS, Liu Z. Lipid rafts and oxidative stress-induced cell death. Antioxid Redox Signal. 2007;9(9):1471-83.

43. Chambers JW, LoGrasso PV. Mitochondrial c-Jun N-terminal kinase (JNK) signaling initiates physiological changes resulting in amplification of reactive oxygen species generation. J Biol Chem. 2011;286(18):16052-62.

44. Win S, Than TA, Fernandez-Checa JC, Kaplowitz N. JNK interaction with sab mediates ER stress induced inhibition of mitochondrial respiration and cel death. Cell Death Dis. 2014;5:e989.
45. Wong GH, Elwell JH, Oberley LW, Goeddel DV. Manganous superoxide dismutase is essential for cellular resistance to cytotoxicity of tumor necrosis factor. Cell. 1989;58(5):923-31.

46. Han D, Ybanez MD, Ahmadi S, Yeh K, Kaplowitz N. Redox regulation of tumor necrosis factor signaling. Antioxid Redox Signal. 2009;11(9):2245-63.

47. Yu J, Zhang L. PUMA, a potent killer with or without p53. Oncogene. 2008; 27(Suppl 1):S71-83.

48. Sade H, Sarin A. Reactive oxygen species regulate quiescent T-cell apoptosis via the BH3-only proapoptotic protein BIM. Cell Death Differ. 2004;11(4): 416-23.

49. Maney NJ, Reynolds G, Krippner-Heidenreich A, Hilkens CM. Dendritic cell maturation and survival are differentially regulated by TNFR1 and TNFR2. J Immunol. 2014;193(10):4914-23.

\section{Publisher's Note}

Springer Nature remains neutral with regard to jurisdictional claims in published maps and institutional affiliations.

\section{Ready to submit your research? Choose BMC and benefit from:}

- fast, convenient online submission

- thorough peer review by experienced researchers in your field

- rapid publication on acceptance

- support for research data, including large and complex data types

- gold Open Access which fosters wider collaboration and increased citations

- maximum visibility for your research: over $100 \mathrm{M}$ website views per year

At BMC, research is always in progress.

Learn more biomedcentral.com/submissions 